\title{
A study of Chinese traditional wetland island settlement combining morphological and narrative analyses
}

\author{
Dongxue Lei, Andong Lu \\ School of Architecture and Urban Planning, Nanjing University. Nanjing, China \\ E-mail: dxlei@smail.nju.edu.cn, alu@nju.edu.cn
}

\begin{abstract}
The Lixiahe region, a low-lying wetland located to the eastern side of the Huaiyang section of the Grand Canal, is characterized by a complex hydrological environment and has changed slowly in the urbanization process. The historical town of Shagou, a representative case of island settlements in this region, has a recorded history of continuous morphological change over six hundred years. Regarding Shagou as a cultural-geographical entity, this article aims at combining morphological analysis and narrative-based cognitive mapping to reveal the characteristic townscape that strongly depends on cultural-geographic complexity. Based on survey work, this article will first define distinguishable plan elements that underpin the spatial form of Shagou: 1) natural context; 2) streets system, and then investigate diachronically different phases of the formation of its spatial structure. On the other hand, based on archiving and data analysis of the oral history study, this article will generate a narrative cognitive map, in terms of paths, nodes, landmarks and areas. In conjunction with fieldwork and documentary records, this study testifies that the method derived from the plan analysis developed by Conzen is applicable to the study of wetland island settlement form in China and that narrative spatial analysis provides important supplemental spatial information. A careful combination of these methods might be used for understanding culturally embedded settlement forms in China.
\end{abstract}

Keywords: Chinese traditional wetland island settlement, morphological transformation, plan analysis, cognitive map

\section{Introduction}

In literal sense, the traditional wetland settlement indicates a historical habitat with clearly environment-responsive characteristics. This is most notable in the case of Shagou, a historical town lying in a wetland of the Lixiahe region. During the complicated evolution of the hydrological environment in the Lixiahe region, the boundary and configuration of the spatial form of Shagou have consistently changed in the span of over 2000 years. The evidence first comes in the form of a land elevating from a shallow bay which is originating from the Yellow Sea, around 2500 years ago (the Warring States
Period). And one group that was well adapted to the unique environment settled down. Based on this resilient topography-responsive form, the habitat experienced significant growth phases. About 1800 ago, the bay transformed into a lagoon and suffered the desalination, which resulting in an emergence of plots of lands. The size of the habitat expanded from one island to a cluster of islands and advanced into the stationary state around 400 years ago (the Ming Dynasty).

However, the morphological changes are not simply a continuous result of natural force, but also a product of social construction, sometimes even radically presented. Benefited from its location on the heartland of the Lixiahe region, 
this settlement has begun to expand because of the increasing number of the migrants since the seventh century (the Tang Dynasty). In response to outside forces originated from the regional trade and population migration, the material forms of the townscape of Shagou became enriched at an unprecedented rate in the fourteenth century AD (the early Ming Dynasty). Henceforward, the role of the town is constantly redefined by the changing social environment, which in turn reshapes the townscape accordingly. Whereas the most intrinsic change happened in the process of urbanization during the 1940s - 1970s, which to a great extend contributes to the form of the town today, a large island surrounded by endless miles of water (Figure 1). This scenic image of the wetland settlement brings Shagou under a new 'social construction', the policy of The Construction of Beautiful Village officially released in 2015, and promotes a process of transforming the town into a tourist town which might probably develop the next evolution of the townscape of Shagou.

It is the interaction of natural force and human force that produces the changeable townscape of Shagou, which might be deduced from archeological evidence of the Lixiahe region $(\mathrm{Wu}, 1996)$ or written references to the Shagou town (Yan, 2016) as that shown above. And can we have a further investigation of the growth of Shagou before the modern period and find some basic principles of the morphological phenomena? The fact is that research on Chinese settlement form is generally handicapped by the lack of information, as Whitehand and $\mathrm{Gu}$ noted (2007). Compared with the city settlement in China, the rural settlement has more limited documentary records of its historico-morphological development, either folklores or literal works. Whereas Shagou is still a potential case with the survival of its traditional form, for the massive restorations and reconstructions have not taken place yet. It is in this context that, the method of analysis is necessary to get beyond consideration of every detail and find supplementary sources of information.

\section{Methodology}

The only cartographic record of the historical Shagou is in one of the military maps made by Japanese (1920), and provides the basic reference to plan analysis. Named 'Shagou', this military map is purposed to show paths on water out of Shagou in all directions. Obviously, Shagou is in an important position for being a center of some function, so it is depicted with details. As this map shows, the Shagou town is on a track of land, which is surrounded but also divided into five parts by water. The outline of the town defined by the circular water routeway present a much similar look from today, however, there are also four water routeways in east-west and south-north directions within the town plan. While these four water routes are completely occupied by roads or buildings today. It is a reasonable presumption that the Shagou town was not on an island but on a cluster of islands and has experienced a metamorphic process.

Identical with the expression of 'Five Groups' from the lore, the town form illustrated on this map has a decisive influence on planning the route of spatial behavior. According to the verbal narrations of the local elders, on the Lantern Fair and the Temple Fair, two of the most significant folk custom tradition, parades with different start and end are both requested to proceed across each group of the 'Five Groups'. From a much narrower perspective of the cognitive sciences in the narrative territory, the verbal narration of the parade route might be treated as a representation of a cognitive map generating from people's embodied experience (Ryan, 2003). The spatial information from a cognitive map can never achieve exact correspondence with the real space, as the verbal narrations do not agree as to the route of the ceremony, but it can be translated into a graphic map which might reveal the spatial relations within the townscape, and thus provides effective supported evidence for the inference from plan analysis (Figure 2).

There is more consistency to substantiate this speculation. A mental model of the spatial relations is repetitive when narrators describe the movements of the ceremonial route, the parade always 'arrives at the temple, and then 
goes over the bridge' or alternatively 'goes over the bridge, and then arrives at the temple'. Where there is a temple there is a bridge and vice versa. The temple and bridge come in pairs as it is shown in the graphic map from people's memorization (Shagou, 2014, pp. 320). Practically, the cognitive map reflects an experience of space which is based on visual cues, the existed material forms: influenced by fengshui for blessing the settlement, the portal of the town is defined by the Zhendong Temple and Zhendong Bridge in the Tang Dynasty (618 - 907), locating on the eastern side of the cluster of islands; The market centre of the town has centered on the location of the Guandi Temple and Wenying Bridge during the period between the Qing Dynasty and the Republic of China (1644 - 1949); The trading market known as 'Chaihang' is near the Chaihang Bridge which was constructed in the Ming Dynasty (1368 - 1644) and blessed by the Caishen Temple which was built on the opposite side of the bridge in the Qing Dynasty (1644-1912).

The cognitive map thus presents sufficient versatility to demonstrate various degrees of detail and precision of the historical townscape, entailing the spatial relations and spatialtemporal information of the material forms that are given meanings. So if we seek to do a plan analysis of the transformation of the town form with the limited planimetric information and the referents from cognitive maps, the preoccupations we focus on must show us not merely a temporal but a spatio-temperal material form, for only by tracing this can we reconnect the cognitive map - the embodied experience to the town form that created it.

\section{Measurement and analysis}

The town plan within the Japanese military map suggests the spatial configuration of the historical town form, and the groups can also be recognized as the islands on a ground plan of today's Shagou according to the fieldwork (Fig. 3). The existence of the cluster of islands is a hint impling a form unit called Duotian (a primarily artificial piled-up land in water) of the traditional wetland settlement, which has been verified by the geographical research on the typology analysis of the rural settlements in the Lixiahe region of the northern Jiangsu plain (Jin, 1982). It is sufficiently pronounced to be very clear that Shagou town was on a cluster of islands

Possibly some time in the second century $\mathrm{BC}$, the origin of Shagou is supposed to be one of these five islands as long ago as the Warring States Period (475-221 BC). Boundaries of the first island may be preliminary judged by the eastern area that defined by three oldest also most important temples (Shagou, 2014, pp.319324; Yan, 2016, pp.252-282; Zhao, 2016, pp.811), the Dutian Temple, Zhendong Temple, Wenchang Temple. The first bridge within this town - the Yingxiu Bridge - indicates the two earlier islands, island $\mathrm{A}$ and island $\mathrm{B}$, for the emergency of the bridge represents the existed human areas on both sides of the bridge. Also with a geographical responsive name over a long time-span justified by the local, island $\mathrm{A}$ is the presumed early habitat that marks the beginning of the existence of Shagou. It is clearly that the outline of the ancient town in each morphological period we have to focus on is the northern and western boudaries.

How the townscape changed in nearly a thousand years following the early morphological period is unknown. It is not until after the mid-Tang dynasty (c. $780-$ 805 ) that Shagou successively shows signs of the westward and the northward extensions of its territory and a basic street system. The sequence of the extensions seems justified both because island $\mathrm{A}$ and island $\mathrm{C}$ as well as island $\mathrm{B}$ and island $\mathrm{C}$ are respectively connected by the Zhendong Bridge and the Renhe Bridge in the Tang dynasty, and because the first business street in the town - the Taiping street (Yan, 2016, p.66) - crossing over the Yingxiu Bridge connecting island $\mathrm{A}$ and island $\mathrm{B}$ previously exists before the Tang dynasty. With regard to the outline of the town in this period, the investigation should continue to turn to the recurrent feature. The location of the Wenying Bridge built in the Tang dynasty (Yancheng Xianzhi, 1583, Wanli edn; Yancheng Xianzhi Chongxiu, 1895, Guangxu edn) marks the existence of island $\mathrm{D}$ and conservatively suggests the western boundary. 
And the Jiangyuan Bridge built in the Song dynasty(960-1638) strengthens the connection between island $\mathrm{C}$ and island $\mathrm{D}$, which has also proved this speculation. While particular evident in the spatial-temporal information of Hongqiao (Yan, 2016, p.272), support the occurrence of the northern stretch to the island E.

The next period is apparently characterized by repetitions of the former street system, which promotes the first westward march of the town centre. This evident occurs when the organization of the streets has began to reuse the structure of the street system formed in the Tang Dynasty since the Yuan Dynasy (1271 - 1368). With simple principles, this street system is applicable to flexibly reorganize space in a block of certain size. Generally, the block is first divided into four parts by the intersection of two streets that in south-north and east-west but, one being in alignment, and then the bigger part will be subdivided by a ' $\mathrm{T}$ ' type street or a short street according to different conditions. In Shagou this morphological period also possibly suggests a new street type. The Nandajie and Zhongxingjie setting along the river makes it expedient for the purpose of material exchanges between water-routes and land-routes.

The advent of the Yushikou (fish market) on the north of the Wenying Bridge in the late Yuan dynasty or the early Ming Dynasty (c. 1368) indicates the beginning of significant changes in the town plan, allowing the years from 1368 to 1644 to be distinguished as a separate morphological period. New additions (Plot E) to the town plan correspond closely with an unparallel number of immigration in businesses. As a result, there is a thriving construction about residential area, temple and market. However, this energy importation not only brings about massive material constructions, but also redefined the townscape of Shagou. Inside the cluster of islands, a fishbone shaped structure access running eastwest is designed. All north-south streets are joint with either the Qiandajie or the Houdajie, two important market streets taking the place of the Taipingjie and the spacing between every two north-south streets is not of approximate distance, but is decided by the number of the neighborhoods sitting abreast for assuring both the equal accesses and the efficiency of paths. Henceforth, the growth of Shagou's built-up area had long ceased leading to a stationary period of almost 300 years. However, the water inside the town was successively replaced by roads during the period between 1940s and 1970s. The reason for this is that the artificial modulation of the natural environment in the Lixiahe region over 2000 years has result in a recession and pollution of the water. And water-route as a traditional transportation mode has become much reduced in significance as the consequent of the changing transportation modes in recent modernization process. Material forms within the townscape were about to go through a metamorphosis from the moment that water disappeared as an expedient to pave the way for development. Hence, A big artificial island with left un-represented town form is indeed the representation of Today's Shagou.

\section{Conclusion}

This study testifies that a combination of narrative and morphological analyses is applicable to the investigation of the transformation of the town form in the terms of the morphological periods and rough boundary of each period, and is enable revealing the predominant phenomena in the process of the transformation. The 'island' (Duotian) presents an environmental responsive meta form with morphological inertia driving the town form to transform in a constant pattern. The street system initially constrained by water evolutes into inextricably interwoven with water. The bridge together with the temple is in part the most significant landmarks defining a specific area in the townscape, but also a traffic node in the street system.

The morphological periods of Shagou as shown in the following:

1. Before Mid-Tang Dyansty (475 BC - c. 780)

2. Mid- Tang Dynasty to Early-Ming dynasty (c. 780 - c.1400)

(a)Mid- and Late Tang Dynasty (c. 780- 907)

(b)Song Dynasty to Yuan Dynasty (960-1368) 
(c)Early Ming Dynasty (1368 - c. 1400)

3. Mid- and Late Ming Dynasty (c.1400 - 1644)

4. Qing Dynasty to Early Republic of China $(1644$ - c. 1928$)$

(a)Early and Mid- Qing Dynasty

(b)Late Qing Dynasty and Early Republic of China $(1840$ - c. 1928)

5. Modern (c. 1945-1970)

Attention to the spatial structure transformation in recent modernization process provides impetus for the points of departure in this study and the methodology based on narrative theory introduces an appropriate method into fieldwork relevant to human's embodied experience. Morphological analysis of this representation of the wetland settlements enables tracking of transformation of the town form in an evolutionary approach, thereby providing an opportunity to challenge the accepted accounts of the traditional wetland settlement, as being merely an intensely visual idea.

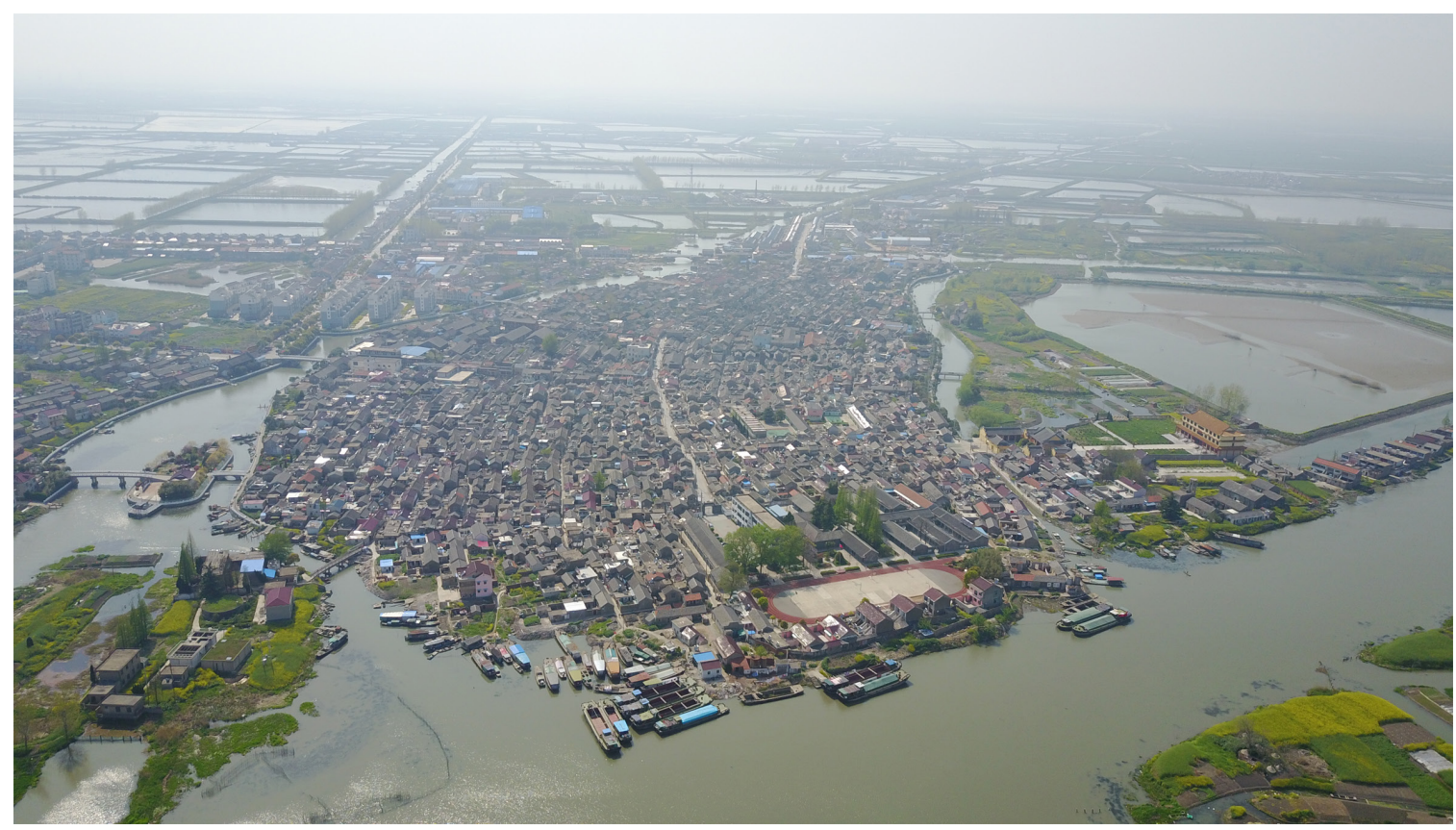

Figure 1. A birds-eye view of the town of Shagou from the northeast direction, 2017. Photographer: Renyuan Hu

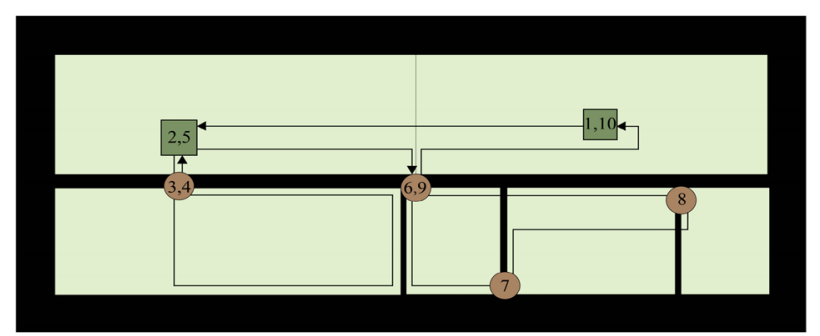

Figure 2.Schematic maps of the verbal narration of the route of spatial behavior, from up to down: parade

route of the Lantern Fair, parade route of the Temple Fair (numbers indicate the sequence of the route)

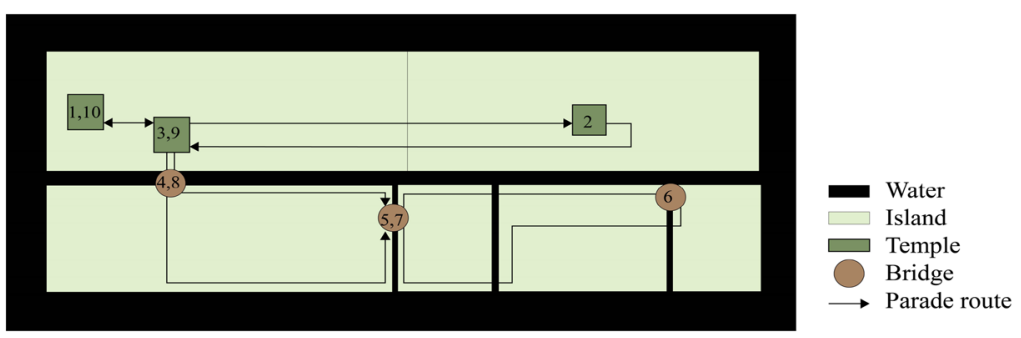




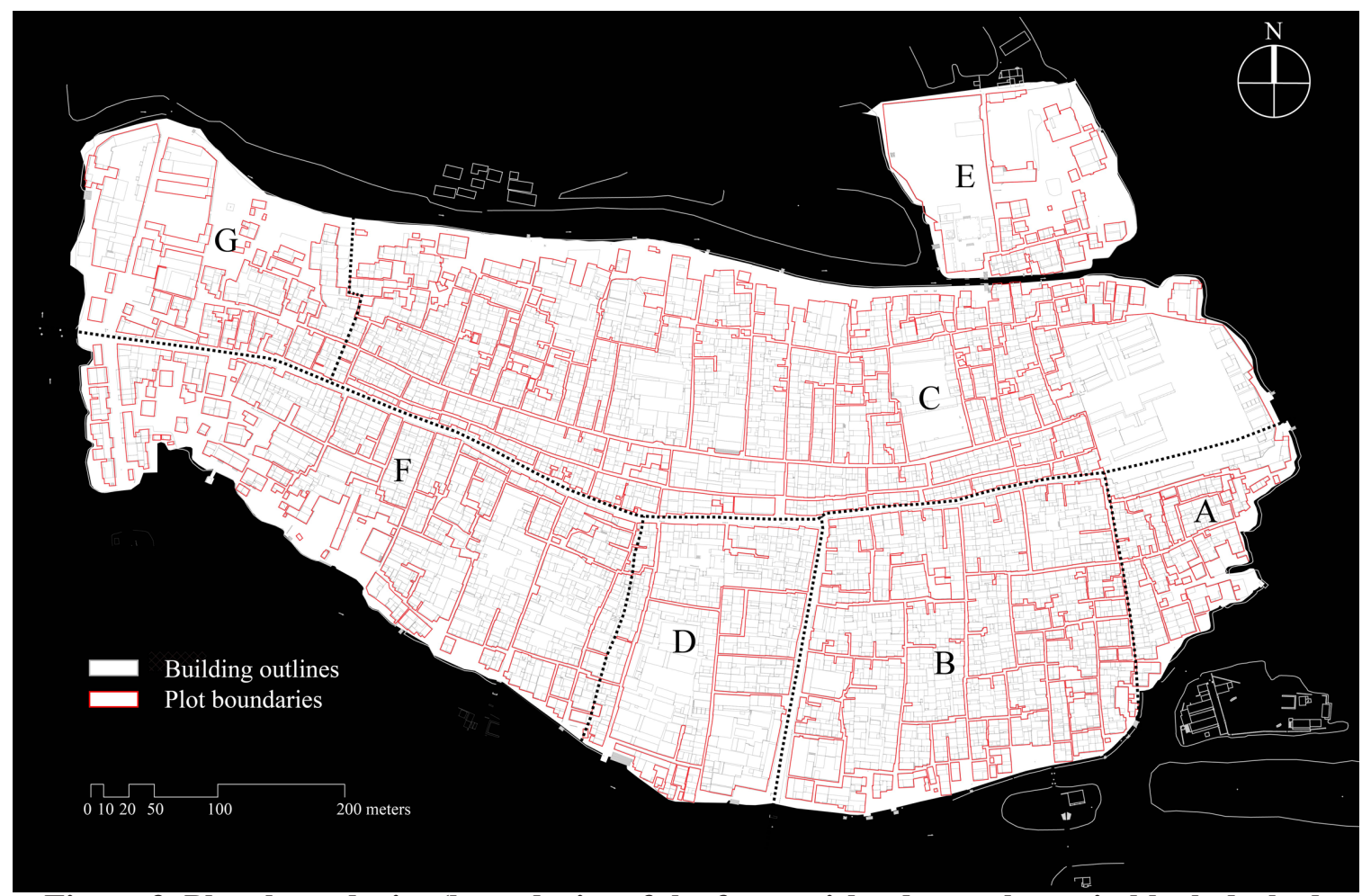

Figure 3. Plots boundaries (boundaries of the former islands are shown in black dashed ) and outlines of the block plans of the buildings: Shagou, c.2009. Based on an unpublished plan prepared by the government of Taizhou, Jiangsu province.

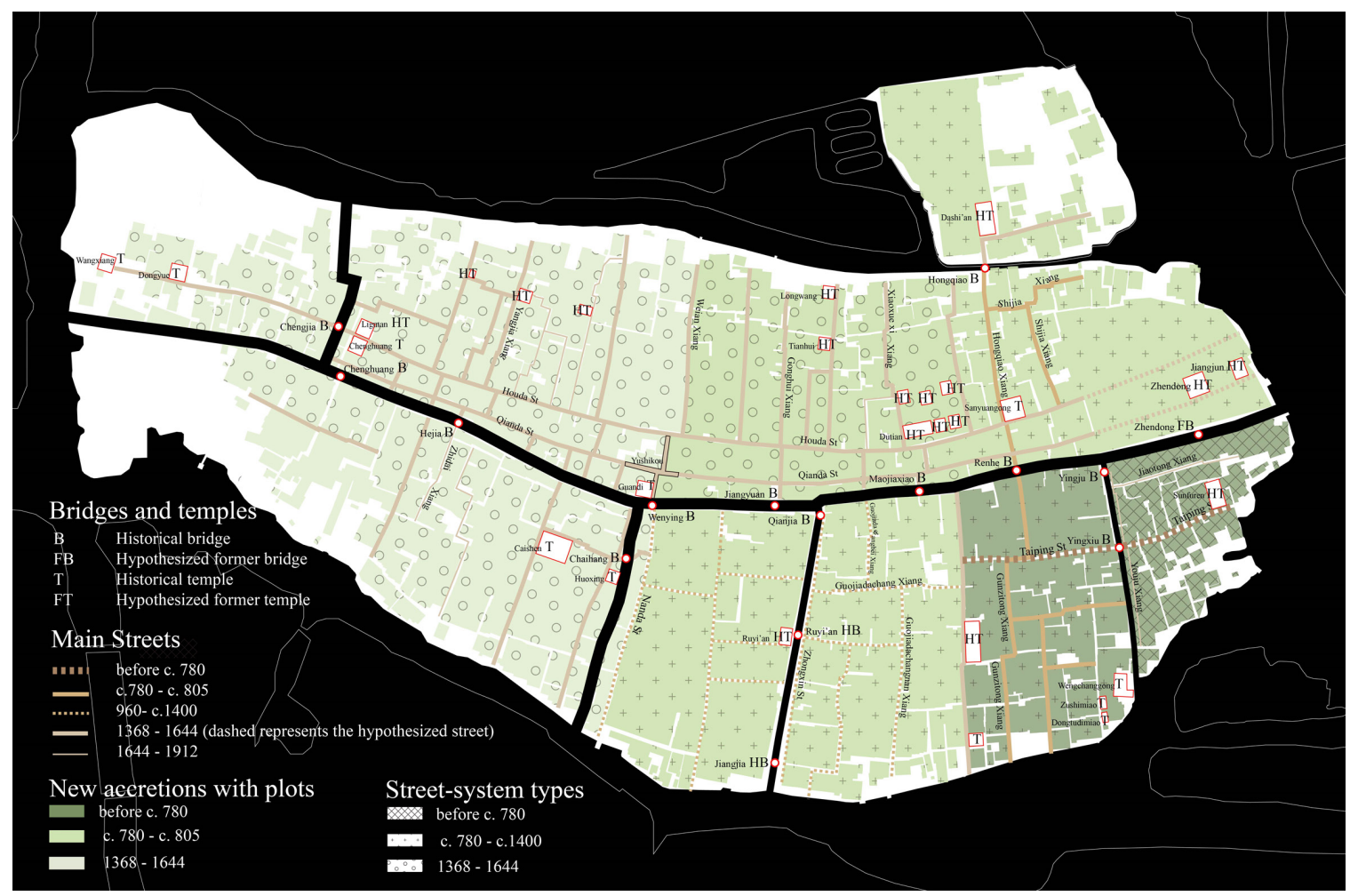

Figure 4. Street - system types and new accretion with plots in the morphological periods of the ancient Shagou, before c. 1945. 


\section{References}

Compiling Committee of The Ancient Town of Taizhou City Series of Books (ed.) (2014) Shagou (Jiangsu People's Publishing.Ltd, Nanjing).

Conzen, M. R. G. (1960) Alnwick, Northumberland: A Study in Town-plan Analysis (London, George Philip).

Jin, Qinming. (1982). Nongcun Junluo Dili Yanjiu - Yi Jiangsusheng Weili (A study of the rural settelments - taking the Jiangsu province as a case ). Geographical Research $3,11-20$.

Long, Jidong and Chen Yushu (ed.) (1895) Yancheng Xianzhi Chongxiu (Recompiling Gazetteer of Yancheng).

Ryan, Marie-Laure. (2003)'Cognitive Maps and the Construction of Narrative Space', in Herman, D. (ed.) Narrative theory and the cognitive sciences (Center for the Study of Language and Information Publication) 214-242.

Whitehand, J. W. R. and Gu, K. (2007) 'Extending the compass of plan analysis: a Chinese exploration', Urban Morphology, 11(2), 91-109.

Wu, Bihu. (1996) Lishi Shiqi Subei Pingyuan Dili Xitong Yanjiu (A study in geographic system of the historical northern Jiangsu plain) (East China Normal University Press, Shanghai).

Yan, Guoqiang. (2016) Shagou mingjian chuanshuo gushi (The folklore of Shagou) (Press of China Federation of Literary and Art, Beijing).

Yang, Ruiyun (ed.) (1583) Yancheng Xianzhi (Gazetteer of Yancheng).

Zhao, Aiming. (2016) Guzhen Shagou zhi (History of the old town of Shagou) (Phoenix Publishing House. Ltd, Nanjing). 